\title{
PENGARUH PHYSICAL SUPPORT DAN CONTACT PERSONEL TERHADAP CITRA (IMAGE) PADA RUMAH SAKIT UMUM DAERAH ANDI JEMMA MASAMBA KABUPATEN LUWU UTARA
}

\author{
Rahmad Solling Hamid ${ }^{1}$, Muhammad Ikbal ${ }^{2}$ \\ Sekolah Tinggi Ilmu Ekonomi Muhammadiyah Palopo \\ ${ }^{1}$ E_Mail: rahmadshamid@stiem.ac.id
}

\begin{abstract}
Abstrak: Tujuan penelitian adalah untuk mengetahui dan menganalisis Pengaruh Physical Support dan Contact Personel terhadap Citra Rumah Sakit Umum Andi Djemma Masamba Kabupaten Luwu Utara. Penelitian yang dilakukan merupakan penelitian explanatory dan menggunakan metode survey. Populasi penelitian ini adalah pasien Rumah Sakit Umum Daerah Andi Jemma Masamba Kabupaten Luwu Utara selama periode penelitian yang berjumlah \pm 1.800 pelanggan/pasien. Sampel penelitian ini ditentukan menurut pendapat (Arikunto, 2003:120), jika populasinya diatas 100 maka diambil prosentasenya, sesuai kemampuan peneliti. Selanjutnya apabila jumlah subyek lebih besar dari 100 dapat diambil antara 10-15\% atau 20-25\% atau lebih sesuai dengan kemampuan peneliti dan diperoleh jumlah sampel sebanyak 180 sampel, dengan teknik yaitu purposive sampling.

Metode analisis data yang dipergunakan dalampenelitian ini adalah analisis deskriptifdan Regresi Linier Berganda, dimana variabel bebasnya terdiri dari Physical Support dan Contact Personal sedangkan untuk variabel dependen yaitu Citra Rumah Sakit. Hasil penelitian dengan menggunakan analisis regresi linier berganda menunjukkan bahwa Berdasarkan hasil uji secara simultan (Uji F) diketahui bahwa tingkat signifikan sebesar 0,000 lebih kecil jika dibandingkan dengan tingkat $\alpha=5 \%$ berarti bahwa semua variabel bebas yang meliputi Physical Support dan Contact Personal, secara bersama-sama mempunyai pengaruh yang signifikan terhadap variabel Citra Rumah Sakit.

Sedangkan untuk (Uji-t) untuk variabel Physical Support berpengaruh positif signifikan terhadap Citra Rumah Sakit. Dengan besaran koefisien regresi yaitu 0,095 atau 9,5\% dengan tingkat signifikan 0,008. Sedangkan untuk variabel Contact Personal memiliki pengaruh positif signifikan terhadap Citra Rumah Sakit. Dengan besaran koefisien regresi yaitu 0,561 atau 56,1\% dengan tingkat signifikan 0,000.
\end{abstract}

Kata kunci: Physical Support dan Contact Personal, dan Citra Rumah Sakit.

\section{PENDAHULUAN}

Dewasa ini industri jasa kesehatan memiliki prospek yang cukup menjanjikan, hal ini dikarenakan jasa pelayanan kesehatan tidak hanya berfokus terhadap pengobatan penyakit tetapi juga mampu memberikan pelayanan kesehtan untuk usaha pencegahan dan peningkatan kesehatan. Peluang ini bisa dimanfaatkan oleh penyedia jasa pelayanan kesehatan untuk memberikan jasa pelayanan kesehatan yang memang menjadi harapan masyarakat sebagai pengguna jasa kesehatan.

Saat ini semakin banyak rumah sakit yang menawarkan pelayanan kesehatan preventif (pencegahan) dan promotif (peningkatan) seperti pemeriksaan untuk chek up, papsmear, dan Fithnes Center (Imam Suroso, 2011:861). Dengan demikian, filosofi rumah sakit adalah bukan mengharapkan orang sakit, tetapi meningkatkan persiapan terhadap kemungkinan sakit dan meningkatkan kesehatan (Trisnantoro, 2005:346).

Kebutuhan terhadap layanan rumah sakit yang bermutu semakin menigkat diikuti dengan semakin membaiknya perekonomian dan derajat kesehatan masyarakat. Dalam beberapa tahun terakhir, industri rumah sakit Indonesia telah mengalami pertumbuhan yang cukup baik seiring dengan diterbitkannya berbagai peraturan dan perundang-undangan yang bertujuan untuk mendorong investasi dan menciptakan kondisi bisnis salah satunya industri jasa rumah sakit yang 
lebih baik. Beberapa upaya yang telah dilakukan untuk meningkatkan pembangunan kesehatan yang lebih berdaya guna, efisien sehingga dapat menjangkau seluruh lapisan masyarakat, meningkatkan kulaitas sumber daya, membenahi peralatan dan obat-obatan serta memperbaiki penampilan Puskesmas dan unit pelayanan kesehatan lainnya seperti rumah sakit umum dan rumah sakit khusus (Imam Suroso, 2011: 861).

Rumah sakit umum sebagai salah satu penyedia fasilitas terhadap pelayanan kesehatan memiliki perananan yang cukup penting dalam pembangunan kesehatan. Rumah Sakit Umum mempunyai misi memberikan pelayanan kesehatan yang bermutu dan terjangkau oleh masyarakat dalam rangka meningkatkan derajat kesehatan masyarakat. Tugas rumah sakit umum adalah melaksanakan upaya pelayanan kesehatan secara berdaya guna dan berhasil guna dengan mengutamakan penyembuhan dan pemulihan yang dilaksanakan secara serasi dan terpadu dengan peningkatan dan pencegahan serta pelaksanaan upaya rujukan.

Keputusan Menteri Kesehatan RI No. 983 Tahun 1992. Dalam rangka menyusun tatanan pelayanan rumah sakit umum, peningkatan serta pengembangan pelayanan kesehatan dan fungsi rumah sakit umum. Departemen Kesehatan RI menentukan standar pelayanan rumah sakit yang berisi kriteria-kriteria penting mengenai jenis disiplin pelayanan yang berkaitan terutama dengan struktur dan proses pelayanan. Selain itu, peningkatan pelayanan kesehatan bukanlah semata-mata ditentukan oleh tersedianya fasilitas fisik yang baik saja, namun yang lebih penting adalah sikap mental dan kualitas profesionalisme para personel dalam memberikan pelayanan (Imam Suroso, 2011:862).

Berdasarkan temuan Hardiman (2003), bahwa sistem pelayanan kesehatan di Indonesia belum baik. Rumah sakit belum mampu menjamin mutu pelayanan kesehatan, misalnya dokter sering terlambat datang, pasien harus menunggu lama untuk mendapatkan pelayanan, belum menyediakan ruang tunggu yang nyaman, belum ada kontinuitas pelayanan, belum bisa menjamin waktu penyerahan obat serta belum mampu membuat sistem peresepan on line lewat komputer. Melihat dari pola perilaku konsumen yang serba instan dan menginginkan pelayanan dengan kualitas prima, dituntuk perhatian khusus dari pihak manajemen rumah sakit umum untuk terus berpikir lebih keras lagi dan terus berupaya untuk meminimalkan kesalahan-kesalahan yang dibuat dalam memberikan pelayanan kepada pasien. Dari permasalahan yang telah dikemukakan diatas bahwa sistem penyampaian jasa yang meliputi physical support dan contact personnel rumah sakit di Indonesia, cenderung belum baik. physical support adalah berbagai fasilitas fisik dan komponen pelengkap dari suatu jasa yang ditawarkan rumah sakit, sedangkan contact personnel adalah tenaga medis, para medis dan non medis yang ikut terlibat dalam penyampaian jasa dan mempunyai kontak langsung dengan pasien dan keluarganya (Imam Suroso, 2011:863).

Selanjutnya dalam sistem penyampaian jasa meliputi physical suport dan contact personel akan mempengaruhi citra rumah sakit. Dalam dunia pemasaran, pembentukan citra perusahaan yang positif akan sangat membantu perusahaan dalam 
kegiatan pemasarannya, karena dalam kondisi persaingan yang sangat ketat maka setiap perusahaan akan berusaha menempatkan dirinya sebaik mungkin dimata konsumen agar dapat dipercaya untuk memenuhi kebutuhannya (Imam Suroso, 2011:863). Menurut (Kotler, 2003:326) bahwa citra merupakan merupakan persepsi masyarakat terhadap perusahaan atau produknya.

RSUD Andi Djemma Masamba merupakan rumah sakit umum kelas C. Rumah sakit kelas C menurut Peraturan Menteri kesehatan RepubliK Indonesia 340/MENKES/PER/III/2010 Nomor memiliki standardisasi pelayanan medik umum yang terdiri dari Pelayanan Medik Dasar, Pelayanan Medik Gigi Mulut, dan Pelayanan Kesehatan Ibu Anak/Keluarga Berencana. Pelayanan gawat darurat harus dapat memberikan pelayanan gawat darurat 24 jam dan 7 hari seminggu dengan kemampuan melakukan pemeriksaan awal kassuskasus gawat darurat, melakukan resusitasi dan stabilisasi sesuai dengan standar.Pelayanan Medik Spesialis Dasar terdiri dari Pelayanan Penyakit Dalam, Kesehatan Anak, Bedah, Obstertri dan Ginekologi.Pelayanan Spesialis Penunjang Medik terdiri dari Pelayanan Anestesiologi, Radiologi, Rehabilitasi Medik dan Patologi Klinik.Pelayanan Medik Spesialis Mulut minimal 1(satu) pelayanan.Pelayanan Keperawatan dan Kebidanan teridiri dari Pelayanan Asuhan Keperawatan dan Asuhan Kebidanan.Pelayanan Penunjang klinik terdiri dari Perawatan intensif, Pelayanan darah, Gizi, farmasi, Sterilisasi Instrumen dan Rekam Medik. Pelayanan Penunjang Non Klinik terdiri dari pelayanan Laundry/Linen, Jasa Boga/Dapur, Teknik dan Pemeliharaan Fasilitas, Pengelolaan limbah, Gudang, Ambulance, Komunikasi, Kamar Jenazah, Pemadam Kebakaran, Pengelolaan Gas Medik dan Penampungan Air bersih.

Dengan begitu kompleknya masalah kehidupan sekarang ini, menyebabkan masalah kesehatan merupakan kebutuhan penting. Oleh karena itu, perusahaan jasa kesehatan diharapkan mampu untuk selalu konsisten pada perannya, dalam memenuhi kebutuhan dan harapan pasien.

\section{KAJIAN LITERATUR DAN PENGEMBANGAN HIPOTESIS}

\section{Sarana dan Prasarana (Physical Support)}

Pengertian sarana dan prasarana dalam pelayanan kesehatan di rumah sakit sesuai dengan Peraturan Menteri Kesehatan Republik Indonesia Nomor 340/Menkes/Per/III/2010 adalah segala sesuatu yang digunakan dalam proses pelayanan kesehatan di rumah sakit, seperti : pelayanan medik, ICU \& UGD, rawat inap, rawat jalan, laboratorium dan administrasi. Fasilitas yang dilihat konsumen merupakan bagian dari wujud nyata yang penting atas keseluruhan jasa yang ditawarkan (Lamb et al,, 2002). Tingkat kenyamanan dalam rumah sakit juga perlu diperhatikan disamping fasilitas dan peralatan.

\section{Kontak Personal (Contact Personnel)}

Contact personnel merupakan semua unsur manusia yang ikut terlibat dalam penyampaian jasa dan mempunyai kontak langsung dengan pembeli. Menurut Nguyen dan Leblanc (2002) contact personnel tersusun dari seluruh karyawan yang berada pada lini depan organisasi dan mempunyai kontak langsung dengan konsumen. Sedangkan Fox et al. (2003) yang menemukan bahwa dokter dan perawat berperanan mendorong kesembuhan 
pasien, terutama keramahan dan perhatian khusus mereka kepada pasien.

\section{Citra Rumah Sakit}

Menurut Kotler (2000), adalah kepercayaan, ide, dan impressi seseorang terhadap sesuatu, image merupakan kesan, impressi, perasaan atau persepsi yang ada pada publik mengenai perusahaan, suatu obyek, orang atau lembaga. Lebih lanjut Citra adalah cara masyarakat menganggap merek secara aktual (Kotler \& Keller, 2012). Bagi perusahaan, image (citra) berarti persepsi masyarakat terhadap jati diri perusahaan. Persepsi ini didasarkan pada apa yang masyarakat ketahui atau yang masyarakat kira tentang perusahaan yang bersangkutan. Oleh karena itulah perusahaan yang sama belum tentu memiliki image (citra) yang sama pula dihadapan orang.

\section{Kerangka Konsep}

Rumah sakit umum daerah diharapkan dapat menciptakan stimulus yang baik, dimana stimulus ini berkaitan erat dengan upaya proses mendesain suatu jasa yang dapat meningkatkan kepercayaan masyarakat. Hal yang dapat dilakukan dengan: 1) physical support seperti berbagai fasilitas fisik yang dimiliki oleh rumah sakit, 2) contact personnel, tersedianya tenaga medis dan non medis yang mempunyai kemampuan memberikan pelayanan, prosedur administratif dan informasi yang dibutuhkan pasien dan keluarganya.

Di dalam mencapai tujuan yang berorientasi terhadap kepuasan pasien, disamping aspek fasilitas rumah sakit, peranan dokter, paramedis dan non medis menjadi sangat penting karena kinerja mereka akan sangat menentukan persepsi dan kinerja yang dirasakan pasien atas pelayanan yang disediakan. Sistem penyampaian jasa meliputi physical support dan contact personnel akan mempengaruhi citra rumah sakit. Dimana pembentukan citra rumah sakit yang positif akan sangat membantu rumah sakit dalam kegiatan pemasaran jasa layanan kesehatan yang disediakan, karna didalam kondisi persaingan yang sangat ketat maka pihak rumah sakit akan memposisikan dirinya dengan sebaik mungkin dimata konsumen agar dapat dipercaya untuk memenuhi kebutuhannya. Hal ini didukung oleh hasil penelitian (Nguyen dan Leblanc, 2002:242) dimana physical support dan contact personel berpengaruh terhadap citra perusahaan. Setiorini (2010) dimana Physical Support mempunyai pengaruh pada citra rumah sakit. Kemudian Rahab (2011) dimana physical support dan contact personel berpengaruh terhadap citra rumah sakit. Kemudian (Imam Suroso, 2011:870) dimana physical support dan contact personel berpengaruh signifikan terhadap citra rumah sakit. Lebih lanjut penelitian yang dilakukan oleh (Putu Lussyani, 2012) dimana physical support dan Contact personel berpengaruh positif dan signifikan terhadap citra rumah sakit dan kepercayaan pelanggan di Instalasi Paviliun Amerta RSUP Sanglah Denpasar, serta Citra rumah sakit berpengaruh positif dan signifikan terhadap kepercayaan pelanggan di Instalasi Paviliun Amerta RSUP Sanglah Denpasar. Kepercayaan (trust) ada jika suatu pihak punya keyakinan (confidence) terhadap integritas dan reliabilitas pihak lain atau menyatakan kepercayaan sebagai kemauan untuk mempercayai pihak lain yang telah diyakini (Morgan dan Hunt, 1994).

Dengan demikian, penelitian ini menggunakan 3 variabel, yaitu 2 variabel 
independen dan 1 variabel dependen. Variabel independen terdiri dari physical support dan Contact Personel kemudian variabel dependen yaitu citra rumah sakit.

Adapun kerangka pikir dalam penelitian ini, dapat disajikan pada gambar 1 berikut:

\section{Gambar 1}

\section{Ke rangka Pikir}

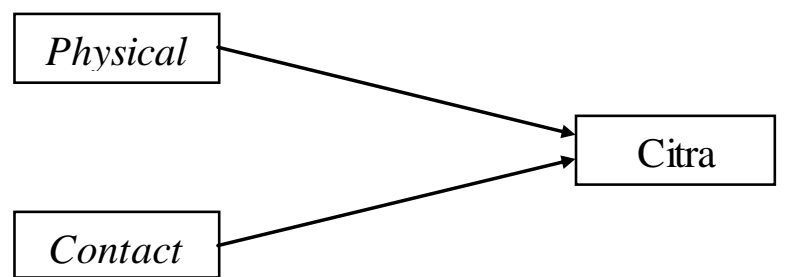

\section{METODE DAN BAHAN}

\section{Metode Pengumpulan Data dan Skala Pengukuran}

Metode pengumpulan data yang digunakan pada penelitian ini adalah dengan metode survey. Metode survey dilakukan secara langsung kepada responden yang dituju dengan menyebar kuesioner. Populasi penelitian ini adalah pasien Rumah Sakit Umum Daerah Andi Jemma Masamba Kabupaten Luwu Utara selama periode penelitian yang berjumlah \pm 1.800 pelanggan/pasien.

Agar penentuan sampelnya memenuhi kriteria yang di kehendaki, maka sampel penelitian ini ditentukan menurut pendapat (Arikunto, 2003:120), jika populasinya diatas 100 maka diambil prosentasenya, sesuai kemampuan peneliti. Selanjutnya apabila jumlah subyek lebih besar dari 100 dapat diambil antara 10-15\% atau 20-25\% atau lebih sesuai dengan kemampuan peneliti (Arikunto, 2003:120). Berdasar pendapat tersebut sampel dapat ditentukan sebanyak 10\% dari pasien Rumah Sakit
Umum Daerah Andi Jemma Masamba Kabupaten Luwu Utara selama periode penelitian atau sebanyak $\quad 180 \quad$ orang pelanggan/pasien.

Tekhnik pengambilan sampel ditentukan dengan purposive sampling yaitu penentuan sampel dengan pertimbangan dan kriteria-kriteria tertentu yang telah ditentukan (Sugiyono, 2004:52). Data keempat variabel tersebut merupakan data ordinal Skala Likert dengan skor 1 sampai dengan 5 .

\section{Uji Validilitas}

Pengujian validitas dilakukan dengan mengkorelasi skor-skor tiap item pertanyaan dengan skor total. Analisis korelasi dilakukan dengan rumus korelasi product moment pearson (Ghozali, 2006), dengan bantuan aplikasi SPSS 23 (Singgih Santoso, 2016).

\section{Uji Reliabilitas}

Reliabilitas atau keandalan dilakukan untuk mengetahui sampai sejauh mana kuesioner yang diajukan dapat memberikan hasil yang tidak berbeda jika dilakukan pengukuran kembali terhadap subjek yang sama pada waktu berlainan. Suatu konstruk atau variabel dikatakan reliable jika memberikan nilai Cronbach Alpha > 0,60 (Ghozali, 2006).

\section{Analis is Regresi Linier Berganda}

Analisis ini dimaksudkan untuk mengetahui besarnya pengaruh Physical Support dan Contact Personel terhadap Citra Rumah Sakit dengan menggunakan persamaan regresi sebagai berikut (Suliyanto, 2011):

$\mathrm{Y}=\mathrm{a}+\mathrm{b}_{1} \mathrm{X}_{1}+\mathrm{b}_{2} \mathrm{X}_{2}+\mathrm{e}$

Di mana : 


$$
\begin{array}{ll}
\mathrm{Y} & =\text { Citra Rumah Sakit } \\
\mathrm{a} & =\text { Nilai intersepsi (konstanta) } \\
b_{1}-b_{2} & =\text { Koefisien regresi } \\
\mathrm{X}_{1} & =\text { Physical Support } \\
\mathrm{X}_{2} & =\text { Contact Personel } \\
e & =\text { error (tingkat kesalahan) }
\end{array}
$$

\section{Instrumen Penelitian}

\begin{tabular}{|c|c|c|}
\hline No & Variabel & Indikator Pengukuran \\
\hline 1 & $\begin{array}{c}\text { Physical } \\
\text { Support (X1) }\end{array}$ & $\begin{array}{ll}\text { 1. } & \text { Fasilitas Gedung } \\
\text { 2. } & \text { Ketersediaan Peralatan } \\
\text { 3. } & \text { Kenyamanan Rumah } \\
& \text { Sakit } \\
\text { 4. } & \text { Kebersihan Rumah Sakit } \\
\text { 5. } & \text { Kestrategisan Lokasi } \\
\text { 6. } & \text { Menu Makanan yang } \\
\text { disediakan }\end{array}$ \\
\hline 2 & $\begin{array}{c}\text { Contact } \\
\text { Personel (X2) }\end{array}$ & $\begin{array}{l}\text { 1. Penampilan tenaga } \\
\text { medis, para medis dan } \\
\text { non medis } \\
\text { 2. Kemampuan tenaga } \\
\text { medis, para medis dan } \\
\text { non medis } \\
\text { 3. } \begin{array}{l}\text { Cara tenaga medis dan } \\
\text { non medis saat }\end{array} \\
\text { memberikan layanan } \\
\text { 4. Keramahan Tenaga } \\
\text { Medis } \\
\text { 5. }\end{array}$ \\
\hline 3 & $\begin{array}{l}\text { Citra Rumah } \\
\text { Sakit (Y) }\end{array}$ & $\begin{array}{ll}\text { 1. } & \begin{array}{l}\text { Pendapat keseluruhan } \\
\text { mengenai rumah sakit }\end{array} \\
\text { 2. } & \begin{array}{l}\text { Pendapat mengenai } \\
\text { kontribusi rumah sakit } \\
\text { untuk masyarakat }\end{array} \\
\text { 3. } & \begin{array}{l}\text { Kesukaan terhadap } \\
\text { rumah sakit }\end{array}\end{array}$ \\
\hline
\end{tabular}

Instrumen yang digunakan untuk melakukan pengukuran variabel dalam penelitian ini adalah sebagai berikut:

\section{Tabel 1}

\section{InstrumenPenelitian}

Sumber: Imam Suroso, 2011

\section{HASIL DAN PEMBAHASAN}

\section{Hasil Pene litian}

Uji Simultan (Uji-F)

Berikut ini adalah uraian hasil pengujian regresi berganda dan output tabel pengujian dengan menggunakan bantuan program SPSS versi 23:

Tabel 2

Uji Simultan (Uji-F)

ANOVA $^{\mathrm{a}}$

\begin{tabular}{|l|r|r|r|r|r|}
\hline Model & $\begin{array}{c}\text { Sum of } \\
\text { Squares }\end{array}$ & Df & $\begin{array}{c}\text { Mean } \\
\text { Square }\end{array}$ & F & Sig. \\
\hline $\begin{array}{l}1 \text { Regressio } \\
\mathrm{n}\end{array}$ & 679.159 & 2 & 339.580 & 273.433 & $.000^{\mathrm{b}}$ \\
$\begin{array}{l}\text { Residual } \\
\text { Total }\end{array}$ & 89.818 & 177 & 1.242 & & \\
\hline
\end{tabular}

Sumber : Data primer diolah, 2016

Berdasarkan hasil pengujian secara simultan (Uji-F) pada tabel 2 diatas diperoleh hasil bahwa nilai signifikan hitung sebesar $0,000<$ tingkat alpha sebesar 0,05. Hal ini berarti bahwa secara simultan variabel Physical Support dan Contact Personel berpengaruh secara signifikan terhadap Citra Rumah Sakit.

\section{Uji Parsial (Uji-t)}

Berikut ini adalah uraian hasil pengujian regresi berganda dan output tabel pengujian dengan menggunakan bantuan program SPSS versi 23: 
Tabel 3

Hasil Uji Parsial (Uji-t).

\begin{tabular}{|c|c|c|c|c|c|c|}
\hline \multicolumn{7}{|c|}{ Coefficients $^{a}$} \\
\hline \multirow{2}{*}{\multicolumn{2}{|c|}{ Model }} & \multicolumn{2}{|c|}{ Unstandardized Coefficients } & \multirow{2}{*}{$\begin{array}{c}\text { Standardized } \\
\text { Coefficients } \\
\text { Beta } \\
\end{array}$} & \multirow[b]{2}{*}{$\mathrm{T}$} & \multirow[b]{2}{*}{ Sig. } \\
\hline & & $\mathrm{B}$ & Std. Error & & & \\
\hline \multirow[t]{3}{*}{1} & (Constant) & -1.715 & .643 & & -2.666 & .008 \\
\hline & Physical Support & .095 & .036 & .133 & 2.669 & .008 \\
\hline & Contact Personel & .561 & .036 & .775 & 15.510 & .000 \\
\hline
\end{tabular}

Sumber : Data primer diolah, 2016

Berdasarkan hasil pengujian secara parsial (Uji-t) pada tabel 3 diatas diperoleh hasil bahwa untuk nilai signifikan hitung masing-masing variabel penelitian dimana untuk variabel Physical Support memiliki nilai signifikan hitung sebesar 0,008 lebih kecil dari nilai alpha sebesar 0,05, hal ini berarti bahwa secara parsial variabel Physical Support berpengaruh positif dan signifikan terhadap Citra Rumah Sakit. Sedangkan untuk variabel Contact Personel memiliki nilai signifikan hitung sebesar 0,000 lebih kecil dari nilai alpha sebesar 0,05 , hal ini berarti bahwa secara parsial variabel Contact Personel berpengaruh positif dan signifikan terhadap Citra Rumah Sakit.

\section{Koefisien Determinasi}

Pada tabel 5 berikut disajikan hasil pengujian koefisien R Square yaitu sebagai berikut:

\section{Tabel 4}

\section{Koefisien $\boldsymbol{R}$ Square}

Model Summary

\begin{tabular}{|c|c|c|c|c|}
\hline Model & $\mathrm{R}$ & $\begin{array}{c}\mathrm{R} \\
\text { Square }\end{array}$ & $\begin{array}{l}\text { Adjusted } \\
\text { R Square }\end{array}$ & $\begin{array}{l}\text { Std. Error of } \\
\text { the Estimate }\end{array}$ \\
\hline 1 & $.869^{a}$ & .755 & .753 & 1.114 \\
\hline
\end{tabular}

Nila $R$ Square $\left(R^{2}\right)$ pada tabel 4 diatas yaitu sebesar 0,755 artinya bahwa variasi perubahan variabel terikat Citra Rumah Sakit sebesar 75,5\% secara bersama-sama disebabkan oleh variabel bebas yang terdiri dari variabel Physical Support dan Contact Personel. Sedangkan sisanya sebesar $24,5 \%$ disebabkan oleh variabel lain yang tidak teridentifikasi kedalam model.

\section{Pembahasan Hasil Penelitian}

Pengaruh variabel bebas secara simultan (Uji F) yang meliputi Celebrity Endorser dan Brand Image Keputusan Pembelian.

Berdasarkan hasil uji secara simultan (Uji F) dalam analisis regresi linear berganda pada penelitian ini diketahui bahwa tingkat signifikan sebesar 0,000 lebih kecil jika dibandingkan dengan tingkat $\alpha=5 \%$ berarti bahwa semua variabel bebas yang meliputi Physical Support dan Contact Personel, secara bersama-sama mempunyai pengaruh yang signifikan terhadap variabel Citra Rumah Sakit.

Besarnya pengaruh semua faktor-faktor yang meliputi Physical Support dan Contact Personel sebesar 75,5\%. Sedangkan sisanya sebesar 24,5\% disebabkan oleh variabel lain yang tidak teridentifikasi kedalam model. 
Total pengaruh perubahan variabel Citra Rumah Sakit yang disebabkan oleh variabel bebas yaitu Physical Support dan Contact Personel yaitu sebesar 75,5\% masih tergolong marginal, ini menunjukkan bahwa asumsi pengabaian faktorfaktor selain dari Physical Support dan Contact Personel ternyata mampu memberikan pengaruh.

Pengaruh variabel Fungsi Physical Support Secara Parsial (Uji t) terhadap Citra Rumah Sakit.

Berdasarkan hasil penelitian dengan pengujian secara parsial (Uji-t) yang menunjukkan bahwa variabel Physical Support berpengaruh positif signifikan terhadap Citra Rumah Sakit dengan koefisien regresi sebesar 0,095 atau 9,5\% artinya dengan meningkatnya variabel Physical Support akan meningkat pula Citra Rumah Sakit diikuti dengan perubahan peningkatan yang signifikan, ini dapat dilihat dari tingkat signifikan yaitu sebesar 0,008. Hasil penelitian ini sejalan dengan penelitian yang dilakukan oleh dengan hasil penelitian yang dilakukan oleh (Imam Suroso, 2011), (Nguyen dan Leblanc, 2002), (Rahab, 2011), (Rahab dan Alisa, 2012), (Setiorini, 2010), dan (Putu Lussyani, 2012) bahwa Physical Support berpengaruh secara signifikan terhadap Citra Rumah Sakit.

\section{Pengaruh variabel Contact Personel Secara Parsial (Uji t) terhadap Citra Rumah Sakit}

Berdasarkan hasil penelitian dengan pengujian secara parsial (Uji-t) yang menunjukkan bahwa variabel Contact Personel berpengaruh positif signifikan terhadap Citra Rumah Sakit dengan koefisien regresi sebesar 0,561 atau 56,1\% artinya dengan meningkatnya variabel Contact Personel maka akan diikuti dengan peningkatan Citra Rumah Sakit secara signifikan, ini dapat dilihat dari tingkat signifikan yaitu sebesar 0,000 . Hasil penelitian ini sejalan dengan penelitian yang dilakukan oleh oleh (Imam Suroso, 2011), (Nguyen dan Leblanc, 2002), (Rahab, 2011), dan (Putu Lussyani, 2012) dengan hasil penelitian yang dilakukan bahwa variabel Contact Personel berpengaruh secara signifikan terhadap Citra Rumah Sakit. Hasil penelitian ini juga ternyata tidak sejalan dengan hasil penelitian yang dilakukan oleh Rahab (2011) dan Puspita (2009), yang menemukan bahwa kontak personal pada kontek rumah sakit pemerintah tidak berpengaruh terhadap citra rumah sakit.

\section{SIMPULAN}

Berdasar pokok permasalahan, tujuan penelitian, hasil analisis dan pembahasannya, dapat dikemukan kesimpulan sebagai berikut :

Hasil uji secara simultan (Uji F) diketahui bahwa tingkat signifikan sebesar 0,000 lebih kecil jika dibandingkan dengan tingkat $\alpha=5 \%$ berarti bahwa Physical Support dan Contact Personel, secara bersama-sama mempunyai pengaruh yang signifikan terhadap variabel Citra Rumah Sakit. Kemudian pengujian secara parsial bahwa untuk variabel (1)Physical Support berpengaruh positif signifikan terhadap Citra Rumah Sakit. Dengan besaran koefisien regresi yaitu 0,095 atau 9,5\% dengan tingkat signifikan 0,008. Dan untuk variabel (2)Contact Personel memiliki pengaruh positif signifikan terhadap Citra Rumah Sakit. Dengan besaran koefisien regresi yaitu 0,561 atau $56,1 \%$ dengan tingkat signifikan 0,000 . 


\section{DAFTAR PUSTAKA}

Arikunto, Suharsimi. 2003. Prosedur Penelitian, Suatu Praktek. Jakarta:Bina. Aksara.

Fox, L. Et al. 2003. The Teaching Pyramid: A Model For Supporting Social Competence and preventing challenging behavior in young Children. Young Children 58 (4).

Ghozali, Imam. 2006. Aplikasi Analisis Multivariate Dengan Program SPSS. Universitas Diponegoro: Semarang.

Hardiman, A. 2003. Rumah Sakit Indonesia Belum Siap Bersaing. Melalui http://www/kompas.com/kompascetakr/0412/22/humaniora1455383html4k.4/21/04.

Kotler, P. 2003. Marketing Management. Engelwood Cliffs: Prentice Hall International Inc. A Division of Simoon and Scuster.

Kotler, Philip. 2000. Manajemen Pemasaran . Erlangga, Jakarta

Kotler dan Keller, 2012, Management Edisi Edition.Pearson. Prentice Hall.

Lamb, et. al. 2001. Pemasaran Buku 1. Jakarta: Salemba Empat

Morgan, R and Hunt, S. 1994. The Commitment-Trust Theory of The Relationship Marketing. Journal of Marketing Research, Vol. 58, July

Nguyen, Nha and Gaston Leblanc. 2002. Contact Personnel, Physical Environment and Perceived Corporate Image of Intangible Services by New Clients. International Journal of Service Industry Management 13: 242-262.
Peraturan Menteri Kesehatan Republik Indonesia Nomor 340/Menkes/Per/III/2010

Puspita, Ita. 2009. Hubungan antara persepsi pasien tentang kualitas dengan citra Rumah sakit Umum Daerah Kabupaten Aceh Tamiang, Tesis. Universitas Sumatera Utara, Tidak dipublikasikan.

Putu, Lussyani. 2012. Pengaruh Sistem Penyampaian Jasa Terhadap Citra Rumah Sakit dan Kepercayaan Pelanggan di Instalasi Pavilium Amerta RSUP Sanglah Denpasar. Tesis. Universitas Udayana. Diakses pada: 28/4/2015

(http://www.pps.unud.ac.id/thesis/detail595-pengaruh-sistem-penyampaian-jasaterhadap-citra-rumah-sakit-dankepercayaan-pelanggan-di-instalasipaviliun-amerta-rsup-sanglahdenpasar.html).

Rahab. 2011. Peran Dukungan Fisik dan Kontak Personal Pada Peningkatan Citra Rumah Sakit Milik Pemerintah. Proceding Seminar Akademik Manajemen dan Bisnis. Universitas Muhammadiyah Surakarta.

Rahab dan Alisa Tri Nawarini. 2012. Peningkatan Citra dan Kepercayaan Masyarakat Pada Rumah Sakit Milik Pemerintah Melalui Perbaikan Sistem Penyampaian Jasa. Jurnal Manajemen Teori dan Terapan.Tahun 1, No.1

Setiorini, Indah Letari. 2010. Pengaruh Physical Support Dan Contact Personel Terhadap Citra (Image) Dan Kepercayaan Pasien Pada Rumah Sakit Umum Situbondo. Skripsi. Universitas Jember, Tidak dipublikasikan.

Singgih Santoso. 2016. Panduan Lengkap SPSS Versi 23. PT. Elex Media Komputindo: Jakarta. 
Sugiyono. 2004. Metode Penelitian Bisnis.

$\mathrm{CV}$. Alfabeta: Bandung.

Suliyanto. 2011. Ekonometrika Terapan: Teori \& Aplikasi dengan SPSS. Andi: Yogyakarta.

Suroso, Imam. 2011. Pengaruh Physical Support dan Contact Personnel terhadap Citra (Image) dan Kepercayaan Pasien pada Rumah Sakit Umum Tuban. Jurnal Aplikasi Manajemen Volume 9 Nomor 3.

Trisnantoro, L. 2005. Aspek Strategis Manajemen Rumah Sakit, Antara Misi Sosial dan Tekanan Pasar. Yogyakarta: Andi Offset. 